\title{
Sobre descrições, retificações e objetividade cientifica: reflexões metodológicas a partir de uma pesquisa sobre condutas sexuais e HIV/aids entre homens com práticas homossexuais'
} On descriptions, rectifications, and scientific objectivity: methodological reflections from a research on sexual behavior and HIV/AIDS among men who have sex with men

Luís Felipe Rios $^{\mathrm{a}}$

(1) https://orcid.org/0000-0002-0767-7845

E-mail: Ifelipe.riosळgmail.com

\section{Karla Galvão Adrião ${ }^{a}$}

(D) https://orcid.org/0000-0002-7411-425X

E-mail: karla.galvao®ufpe.br

aniversidade Federal de Pernambuco, Departamento de Psicologia, Programa de Pós-graduação em Psicologia, Laboratório de Estudos da Sexualidade Humana-LabEshu. Recife, PE, Brasil.

\section{Correspondência}

Luís Felipe Rios

Av. da Arquitetura, $\mathrm{CFCH}, \mathrm{s} / \mathrm{n}, 7$ andar, Cidade Universitária. Recife, PE, Brasil. CEP 50670-901.

\section{Resumo}

Este ensaio reflete sobre a positividade de conhecimentos produzidos por abordagens etnográficas, a partir da discussão dos meandros de uma pesquisa sobre homens que se relacionam sexualmente com outros homens e vulnerabilidade ao HIV/aids. Propõe como falsa a oposição entre metodologias explicativas e compreensivas, uma vez que ambos os princípios estão presentes, em maior ou menor grau, em todas as investigações em ciências humanas e sociais. Nessa linha, põe em xeque critérios de cientificidade do "senso comum científico" que fazem o uso da matemática como o demarcador. Exemplifica como a descrição crítica do próprio ato de pesquisar e das retificações sobre os obstáculos ao conhecimento, identificados no próprio caminho, conferem objetividade aos conhecimentos produzidos. O diferencial etnográfico em relação a outras abordagens de ênfase compreensiva é a explicitação da própria experiência dos pesquisadores no campo como recurso crítico e analítico.

Palavras-chave: Epistemologia Científica; Metodologia; Ciências Humanas e Sociais; Inquérito Comportamental; Etnografia.

\footnotetext{
O projeto "Contextos sociais e marcações subjetivas na vulnerabilidade de homens jovens que fazem sexo com homens ao HIV/aids" vem sendo financiado pelo CNPq (processos 405259/2012-3, 470088/2013-3, 305136/2014-3, 310468/2018-3), foi aprovado pelo Comitê de Ética em Pesquisa com Seres Humanos da Universidade Federal de Pernambuco (UFPE) e contou com apoio institucional do Programa de Pósgraduação em Psicologia (PPGPsi) da UFPE, que, com recursos do PROAP/CAPES, apoiou a tradução deste artigo. Além do CNPq, do PPGPsi e da CAPES queremos agradecer às professoras Vera Paiva e Sandra Brignol que contribuíram com a pesquisa e à equipe de estudantespesquisadores que participaram da coleta de dados, muitos deles contando com bolsa de iniciação científica da UFPE/CNPq e FACEPE.
} 


\section{Introdução}

From a research about men who have sex with men and vulnerability to HIV/AIDS, this essay reflects on the positivity of knowledge produced by ethnographic approaches. Once both explanatory and comprehensive methodologies are present, to a greater or less extent, in all investigations in human and social sciences, it proposes as false the opposition between both principles, questioning the scientific criteria of "scientific common sense" that use mathematics as demarcator. With that, the text exemplifies how the critical description of the act of researching and rectifying the obstacles to knowledge, identified in the path itself, grants objectivity to the knowledge produced. When compared to other comprehensive approaches, the ethnographic differential consists of explaining the researchers' field experience as a critical and analytical resource.

Keywords: Scientific Epistemology; Methodology; Humans and Social Sciences; Behavioral Survey; Ethnography.
O etnógrafo "inscreve" o discurso social: ele o anota. Ao fazê-lo, ele o transforma de acontecimento passado, que existe apenas em seu próprio momento de ocorrência, em um relato, que existe em sua inscrição e que pode ser consultado novamente.

(Geertz, 1987, p. 14).

Este ensaio discute os meandros de uma pesquisa etnográfica sobre as condutas sexuais de homens que fazem sexo com homens (HSH), viabilizada por observação participante, entrevistas biográficas, inquérito comportamental, entrevistas temáticas e análise documental. A possível estranheza que o inquérito comportamental (técnica quantitativa) pode causar, quando se pensa em um estudo etnográfico, será a base a partir da qual teceremos as reflexões que aqui apresentamos.

0 ato de pesquisar é, em metáfora utilizada por Rubens Alves (2006), um exercício de captura. Para tal, precisamos forjar nossos instrumentos de trabalho de modo que, como os anzóis e redes de um experiente pescador, apanhemos apenas os peixes desejados: as respostas empíricas às nossas questões de investigação.

Conhecer o mundo implica, já de início, classificar e selecionar (Wittgenstein, 2017). Cabe-nos, por meio de nossos instrumentos de pesquisa (teorias e técnicas), retirarmos o que nos interessa da amplidão da realidade. Como sugere Clifford Geertz (1987), permitir a inscrição dos fenômenos em uma modalidade de registro que possibilite operações intelectuais pelas equipes de pesquisadores(as), e medie a comunicação entre aqueles(as) que compõem a comunidade de interessados(as) e legitimados(as), para avaliar o conhecimento produzido (Latour, 2001).

Nas ciências humanas e sociais (CHS) os embates sobre o uso da matemática nas pesquisas são apreendidos a partir de dois modos de classificar o que resulta do trabalho científico: a explicação e a compreensão (Dilthey, 2002). A primeira noção é caudatária dos positivismos e de suas premissas de se aplicar aos estudos de pessoas e coletividades humanas os mesmos dispositivos usados nas ciências naturais (Giddens, 1998). Nesse campo, 
a produção do conhecimento científico é feita por meio de aparatos cuidadosamente montados (por exemplo, experimentos e inquéritos) que possibilitem a testagem sobre a existência de relações entre os elementos (variáveis) que, hipoteticamente, concorrem para um dado fenômeno.

O recurso ao cálculo estatístico se dá como forma de averiguar a existência de relações causais ou, pelo menos, associações entre estes elementos, de modo a propor leis ou explicações sobre o fenômeno. O uso da estatística vai implicar no estabelecimento de amostragens que, idealmente, devem ser representativas do universo investigado, tanto numericamente como nas maneiras de arregimentar os voluntários da pesquisa, de modo que todos os casos tenham a mesma chance de participar da pesquisa (Goode; Hatt, 1972).

Já nos estudos compreensivos, a pretensão explicativa é abandonada por considerar-se que os fenômenos humanos são atravessados e constituídos por uma historicidade multideterminada. Para toda e qualquer coleta de dados é preciso também considerar as individualidades humanas que modulam suas condutas/respostas em função de emoções, pensamentos e vontades. Esses elementos perturbariam as modelagens positivistas clássicas usadas para abordar os objetos de conhecimento científico e as pretensões de encontrar leis para os fenômenos humanos, exigindo, no mínimo, que se coloquem em perspectiva os resultados obtidos por meio dos dispositivos clássicos de investigação de inspiração explicativa (Dilthey, 2002).

No campo compreensivo, a meta dos estudos é, por meio da observação dos fenômenos e dos significados para os que deles são partícipes, aprofundar suas descrições, identificando os elementos que concorrem para suas emergências e para as conexões entre eles. Em suma, a questão do sentido, eminentemente humana, é o principal demarcador na diferenciação do manejo de métodos e técnicas de investigação, porque também o é na própria demarcação do objeto de estudo (Dilthey, 2002).

A compreensão vai significar o estabelecimento de interpretações sobre as principais conexões identificadas entre os elementos. A pretensão de construir uma amostragem representativa será, quase sempre, inalcançável, seja no que se refere a números, seja nos modos de alcançar os voluntários das pesquisas. Mas isso não significa dizer que há um abandono do cálculo e mesmo da estatística como um instrumento de trabalho científico. Entendemos que não há necessariamente uma oposição entre explicação e compreensão, sugerindo que talvez seja mais interessante situá-los como princípios, que podem estar presentes em diferentes articulações de técnicas de investigação, do que como atributos categoriais monotéticos.

Perdendo de vista a discussão propriamente epistemológica e direcionando para o debate sobre o número, são três as posições que olham parcialmente o método, fetichizando-o (Bachelard, 2005) positiva ou negativamente como demarcadores de cientificidade, no "senso comum científico". Há quem diga que, na ausência dos requisitos estatísticos para produzir amostras representativas e medir ou testar as associações, os estudos compreensivos careceriam de rigor e replicação e, por tanto, não seriam científicos. Outros, supostamente mais moderados, sugerem que estudos compreensivos são admissíveis enquanto não é possível aplicar métodos capazes de produzir explicações, ou como modo de se aproximar de objetos novos, ainda pouco conhecidos. Há ainda a perspectiva de que, dada a constante mudança dos fenômenos humanos, é impossível se chegar a leis e/ou explicações. Neste caso, há uma quase negação ou abandono de uma reflexão sobre as possibilidades que a matemática pode oferecer para a análise e representação dos fenômenos humanos. Mas, ainda que superemos essa disputa, uma questão permanece: é possível ter critérios convergentes sobre a cientificidade dos estudos, frente a uma diversidade de métodos e técnicas de investigação, explicativos e compreensivos, em CHS?

São várias as propostas utilizadas pelos epistemólogos e metodólogos para avaliar a cientificidade (verdade e/ou objetividade) do conhecimento científico. Retomamos a proposta de Gaston Bachelard (2005) que foca mais nos processos de construção do conhecimento do que os resultados da pesquisa. Ele propõe que o senso comum, as sensações primeiras e as próprias teorias podem se constituir em obstáculo ao conhecimento se, por qualquer motivo, forem fetichizados, tornando-os impenetráveis ao pensamento reflexivo. Coloca nesse bojo a própria 
matemática, quando ela perde a capacidade de servir de instrumento para o processo de conhecer, como uma linguagem universal para manipular e/ou apresentar dados, e os próprios números e equações são tomados como um fim para o qual tudo deve convergir.

Para Bachelard (2005), a objetividade do conhecimento não se dá a priori, quando se define um método correto para investigar um dado fenômeno e as questões que ele suscita. A objetividade do conhecimento científico advém da ação de enfrentar analiticamente os obstáculos que vão se fazendo ao longo do processo de conhecer. Ele propõe a experiência científica como um exercício de retificação de erros do próprio processo, uma reflexão sobre o caminho, uma discussão propriamente metodológica, onde a simples apresentação dos procedimentos da pesquisa é insuficiente para garantir a cientificidade.

Na nossa compreensão, a proposta de Bachelard (2005) permite sair da falsa dicotomia do "quali/ quanti” que se estabeleceu nas CHS, endereçandonos para a reflexão sobre as diferentes estruturas de coleta, análise, representação e interpretação (linguísticas, matemáticas e gráficas) de dados presentes nas técnicas de investigação. Precisamos refletir sobre como, em dada pesquisa, produzem-se proposições que se tornam referentes circulantes, capazes de representar e de dar inteligibilidade à cadeia de transformações que caracteriza o processo de construção do conhecimento científico (Latour, 2001).

\section{Como inscrevemos}

A pesquisa teve início em janeiro de 2013 e encontra-se em andamento enquanto este artigo está em processo de redação. Seu universo de investigação são as redes de sociabilidade de HSH da Região Metropolitana do Recife (RMR). Na época composta por 14 municípios e com uma população estimada, em 2016, em 3.940.456 habitantes, a RMR está localizada em Pernambuco, Nordeste do Brasil. Recife, capital do estado, é o maior dos municípios, com população estimada em 1.625 .583 pessoas e é nele onde estão os principais estabelecimentos comerciais e locais públicos de homossociabilidade da região.

O trabalho de campo foi composto por seis fases de investigação que se interconectam ao longo da coleta de dados. A primeira fase teve como instrumento a observação participante, desde o início da pesquisa, em 2013, até fevereiro de 2017. Destacamos que a escolha dos lugares se deu por conhecimento prévio, uma vez que muitos deles já vinham sendo objeto de estudos etnográficos realizados no grupo de pesquisa onde o projeto se situa. Ao longo da pesquisa, as diferentes fontes de dados ajudaram a identificar outros espaços, incluídos como lugares observados.

A segunda fase consistiu na realização, transcrição e análise de 25 entrevistas com foco biográfico junto aos HSHs, com idades variando entre 18 e 38 anos. A análise dos dados permitiu uma primeira compreensão dos fenômenos em investigação e ofereceu elementos para ampliar os lugares de observação, ajustar o instrumento do inquérito comportamental, e o roteiro de entrevista para a quarta frente de trabalho, de modo a aprofundar a investigação.

A terceira fase aconteceu entre janeiro de 2016 e fevereiro de 2017 e consistiu na realização de um estudo de corte transversal que investigou o perfil sociodemográfico da população HSH, marcadores sociais, conhecimentos, atitudes e práticas sobre sexualidade e saúde sexual, bem como percepção de risco para HIV. Foi utilizado um instrumento com a maior parte das questões fechadas, de aplicação individual com auxílio de um entrevistador. O questionário foi elaborado a partir dos instrumentos utilizados em pesquisa de conhecimentos, atitudes e práticas sobre sexualidade e HIV/aids (Pascom; Arruda; Simão, 2011; Raxach et al., 2007) e dos resultados das fases anteriores (Rios et al., 2019a, 2019b). Participaram do estudo 380 homens com práticas homossexuais residentes na RMR, com idades variando entre 18 e 51 anos.

A quarta fase consistiu na realização de 24 entrevistas com HSHs de 18 a 51 anos, respondentes do inquérito sobre as dinâmicas dos lugares de homossociabilidade que frequentavam e sobre práticas alternativas às da saúde pública para se prevenir do HIV.

Na quinta fase retomamos as observações participantes, a partir de março de 2019, de modo que percebermos as mudanças nos espaços de sociabilidade e nas redes de HSHs. Além disso, incluímos pesquisa documental sobre campanhas de prevenção ao HIV/aids na RMR. Finalmente, 
na sexta fase retomamos a realização de entrevistas na perspectiva de continuar investigando as dinâmicas dos lugares de homossociabilidade e as práticas alternativas de gestão de risco para o HIV, considerando as mudanças nas políticas de prevenção do HIV. Até o momento foram entrevistados 36 HSHs de idades variando entre 18 e 38 anos.

Esta tem sido uma pesquisa realizada a muitos olhos, ouvidos e mãos, envolvendo pesquisadores em diferentes níveis de formação. As entrevistas foram realizadas por estudantes de graduação, de ambos os sexos. $O$ inquérito foi aplicado apenas por estudantes do sexo masculino. As observações nos espaços de homossociabilidade foram realizadas apenas por homens gay-identificados (um dos coordenadores da pesquisa e alguns dos estudantespesquisadores). Estudantes de mestrado e doutorado também estiveram envolvidos/as, conduzindo formações teóricas e metodológicas dos estudantes de graduação, supervisionando o trabalho de campo e/ou colaborando nas análises.

Do ponto de vista teórico, a pesquisa entende a suscetibilidade ao HIV e outros agravos aos HSHs, a partir da perspectiva da vulnerabilidade e dos Direitos Humanos, realizando conexões entre aspectos sociais, programáticos e subjetivos, que atravessam os contextos socioculturais e intersubjetivos dos participantes da pesquisa (Ayres, Paiva, Buchalla, 2012). A sexualidade e o gênero são analisados a partir de abordagens feministas (Rubin, 1975), concebidos como construções socioculturais que organizam subjetividades e práticas sociais. Temos pensado os enredos sexuais e os usos de medidas de proteção a partir de um quadro conceitual que busca se aproximar das dimensões mais somáticas dos processos de produção de sentidos. Inspirados em Judith Butler (2003), denominamos "estilizações corporais" as figurações das classificações (inerentes à operação dos diferentes sistemas sociais). Elas são composições sociais, resultados estéticos do agenciamento de elementos corporais (constituição física, gestual, vestuário, adorno, sotaque etc.). Quando alguém é adscrito a uma estilização por uma configuração imagética, há a produção de sentidos (disposições, significados, valores, emoções) que vão mediar as ações (Rios et al., 2019a, 2019b; Rios, 2020).
Apresentados os pilares teóricos e os procedimentos da coleta de dados da pesquisa, é possível, voltando para os caminhos efetivamente percorridos em algumas das fases de investigação, aprofundar a discussão sobre o manejo dos instrumentos.

\section{Redes de tramas estreitas}

O processo de pesquisar é um ato de reduzir. Do ponto de vista científico é impossível conhecer a totalidade das experiências humanas. As questões de pesquisa são dispositivos de simplificação. Elas implicam em, informados por uma teoria, conectar elementos (variáveis) de uma dada realidade a fim de produzir respostas antecipadas (hipóteses ou tipos ideais), de modo que possam orientar o trabalho de investigação, possibilitando explorar empiricamente o fenômeno em estudo (Weber, 1997).

As hipóteses, como sugere Karl Popper (2006), devem ter formulações que permitam as suas falibilidades. Os instrumentos de trabalho de coleta e análise dos dados ideais são aqueles que permitem a expressão do sim e do não às questões de trabalho. Algumas abordagens qualitativas, em especial o fazer etnográfico, permitem um certo transbordar da realidade em relação às questões de pesquisas e hipóteses. Os protocolos de pesquisa nesses campos preveem não apenas modos de se chegar, em termos de sim ou não, às hipóteses. 0 trabalho de campo, muitas vezes faz aparecer novos elementos que se agregam às conexões inicialmente estabelecidas, possibilitando o surgimento de novas hipóteses durante a própria pesquisa (Becker, 1997).

Voltando à metáfora da pesca, as redes de tramas mais estreitas são as que pegam uma maior variedade de animais marinhos, indistintamente, e as de trama larga são as mais especializadas, pegando apenas animais maiores e os peixes de maior interesse gastronômico. As redes com as quais a etnografia trabalha possuem tramas bastante estreitas. 0 plano de observação e o diário de campo são instrumentos que concretizam de forma muito vaga as perguntas e as respostas prévias no sim ou não. Contudo, isso não é ruim.

Um exemplo pertinente foi o modo como o surgimento da covid-19, em 2019, pode ser investigado no âmbito de nossa pesquisa, sem a necessidade de 
mudança nos protocolos de investigação. A única alteração foi a do deslocamento da maior parte de observações e entrevistas para a dimensão online, já prevista como local de pesquisa, dada sua relevância para a sociabilidade de HSHs. A análise de 16 entrevistas realizadas durante o primeiro ano da pandemia permitiu abordar importantes questões, como a do encontro com parceiros sexuais casuais que não moram na mesma residência e sobre a sociabilidade de lazer na interface com o uso de medidas de distanciamento social, capazes de aumentar a circulação do vírus na sociedade. Possibilitou também estabelecer relações com temas caros ao nosso trabalho, como a vinculação entre parceiros, a produção de confiança e a despreocupação com modos de prevenção (Rios et al., 2019b), presentes entre os HSHs nas duas pandemias (Rios, 2021).

Em adição, os objetos das etnografias têm sempre a ver com os sujeitos imersos na totalidade que os constitui, onde as variáveis nem sempre têm a possibilidade de controle. Na etnografia, a imersão numa realidade nova possibilita e exige o estranhamento: um recurso teórico-metodológico para que o objeto possa ser analisado (Peirano, 2014). No caso das observações, passado um certo tempo do trabalho de campo, em que tudo parece ou deve ser apreendido como novo - por meio de recursos técnicos -, as recorrências vão se mostrando. Fenômeno que também vai provocando no pesquisador o sentimento de familiaridade. De forma um tanto mais objetiva e pragmática, as páginas do diário de campo, o primeiro passo da inscrição, estão repletas de descrições sobre os fenômenos, e a identificação das recorrências só é possível se formos capazes de contar (Becker, 1997). Um processo que também envolve testar as conexões inicialmente estabelecidas, no contraste com os elementos que estiveram presentes: no que foi mais recorrente e também nos eventos raros que, em certa medida, se destacam frente ao que mais se repete.

Se a pesquisa envolve entrevistas, o mesmo procedimento poderá ser utilizado quando se opta por certos modelos de análise temática ou de conteúdo (Minayo, 2012). No nosso caso, por exemplo, depois das 25 entrevistas realizadas na segunda frente do trabalho de campo, a equipe se reuniu e, em função dos objetivos da pesquisa, elaborou respostas empíricas a partir das muitas narrativas coletadas. Dessa conversa inicial sobre os dados, grandes temas emergiram, alçados ao estatuto de eixos e categorias de análise: 1) Opiniões sobre: posições eróticas, posições de gênero e assumir-se; 2) Disposições sobre gostos eróticos com parceiros fixos e casuais; 3) Práticas que consistiam em categorizar fragmentos de cenas e experiências narradas em duas subcategorias: curso de vida e práticas eróticas, e curso de vida e performatividade; 4) HIV/aids e Prevenção; 5) Estigmatização. Além desses cinco eixos, havia um sexto, o Eixo o, onde foram alocados os dados sociodemográficos (idade, raça/cor, posição sexual, estilização de gênero, escolaridade, renda individual, profissão/ocupação, religião), permitindo identificar o estabelecimento de relações entre os marcadores sociais e os temas e subtemas presentes em cada categoria de análise.

Esses eixos, categorias e subcategorias foram organizados em um quadro analítico em Excel, como exemplifica a Quadro 1, com os eixos de 1 a 3 , suas categorias e subcategorias. Em um segundo momento o quadro foi alimentado por fragmentos das entrevistas que remetem às categorias estabelecidas.

Quadro I- Fragmento do quadro de análise

\begin{tabular}{|c|c|c|c|c|c|c|c|c|c|}
\hline \multicolumn{7}{|c|}{ Opiniões sobre (Eixo I) } & $\begin{array}{l}\text { Disposições } \\
\quad(\text { Eixo 2) }\end{array}$ & \multicolumn{2}{|c|}{$\begin{array}{c}\text { Práticas (cenas, experiências) } \\
\text { (Eixo 3) }\end{array}$} \\
\hline \multicolumn{3}{|c|}{ Posições eróticas } & \multicolumn{2}{|c|}{ Posição de gênero } & \multicolumn{2}{|c|}{$\begin{array}{l}\text { Assumir-se } \\
\text { (voz, gestualidade, } \\
\text { ser gay, ser boy, ser } \\
\text { pintoso/dar pinta, } \\
\text { se montar) }\end{array}$} & Gosto erótico & $\begin{array}{l}\text { Curso de vida } \\
\text { e práticas } \\
\text { eróticas }\end{array}$ & $\begin{array}{l}\text { Curso de vida e } \\
\text { performatividade }\end{array}$ \\
\hline Ativo & Passivo & Versátil & Masculinizado & Feminilizado & Discreto & Assumido & $\begin{array}{l}\text { Atributos } \\
\text { positivos dos } \\
\text { parceiros }\end{array}$ & Sacanagem & Performance \\
\hline
\end{tabular}


O passo seguinte foi identificar os "temas", ou seja, as variações de posicionamento sobre dado assunto, e estabelecer relações com os marcadores do quadro sociodemográfico ou com outras categorias. Um processo que envolve ações de discernir, classificar e contar. Como exemplo, tomamos uma questão, importante na literatura, que aponta que as estilizações de gênero são eixos organizadores da sociabilidade homossexual (Rubin, 1975; Fry, 1982; Parker, 2002). Questionamos aos nossos dados: existe entre os HSHs da RMR relação entre estilizações de gênero e desejo?

Perguntamos aos 25 entrevistados da segunda fase como se classificavam em relação ao gênero, ao qual, maciçamente responderam "sou homem". Resposta que impediria análise da relação entre estilizações corporais e outros marcadores e temas elemento necessário para também explorar a operação do sistema sexo-gênero na configuração das vulnerabilidades ao HIV, à violência e ao sofrimento, importantes hipóteses de nossa pesquisa.

A imersão etnográfica, possibilitada por observações e pela própria experiência intersubjetiva entre entrevistado e entrevistador, permitiu que a equipe realizasse um interessante movimento de inscrição analítica das posições de gênero dos participantes. Por meio do conceito de estilizações corporais o grupo refletiu sobre as categorias nativas de gênero. Num primeiro momento, boy/masculino e pintosa/feminino emergiram como categorias êmicas para classificar os homens. Chegando a esses dois tipos ideais, realizamos a classificação dos informantes. A ideia era de, seguindo a sugestão de Max Weber (1997), utilizá-los como hipóteses de trabalho mais pragmáticas para tensionar o discurso nativo e permitir aprofundar a compreensão dos significados das categorias de gênero, e, se fosse o caso, refutar integralmente ou parcialmente os tipos. Masculinizado e feminilizado entraram na grade de análise como categorias a serem preenchidas com as falas dos informantes, permitindo adensar os significados da classificação nativa.

A partir do relato de cenas sobre os parceiros sexuais, alocadas no eixo 2 , verificamos que todos desejavam homens másculos. No entanto, os másculos desejados pelas pintosas pobres não eram descritos do mesmo modo que os boys.
Mas, só fomos perceber isso quando nos questionamos sobre os parceiros das pintosas. Ou seja, se a feminilidade era objeto de desprestígio erótico pelos boys, com quem as pintosas efetivamente estabeleciam parcerias sexuais?

A resposta estava lá mesmo, na categoria “atributos positivos do parceiro". Por exemplo, na linha dedicada ao sujeito 1, Antônio, 38 anos, pintoso, versátil mais ativo, na subcategoria casual, estava transcrito o seguinte fragmento de entrevista:

E: Qual o tipo de rapaz que tu gostas? Como é ele assim, a aparência? A: Moreno $\varepsilon$ : Moreno? A: $\varepsilon$, moreno e barrigudo. $\varepsilon$ : $\varepsilon$ é? Barrigudo? A: $\varepsilon$, eu gosto. E: Cabelo e tal... Alto ou baixo, tanto faz? A: Não, tanto faz. $\varepsilon$ : Tu preferes mais magro, mais gordo? A: Mais gordinho, mais gordinho. Com barriguinha. E: Mas tudisseste que gostas de homem, não gosta de homossexual. Então tu preferes que ele não aparente? A: Não, não, não. Transar com homossexual não gosto não. Mas esse negócio de trocar... Dizem trocar, né, eu não gosto não com homossexual, não. Só com cafuçu mesmo. O cara que é cafuçu. E: Como é o cara cafuçu? A: O cara cafuçu é assim: "que eu rolo com porra de frango"! $\varepsilon$ : Enrola com o quê? A: 'E eu rolo com porra de frango'. Quando tá bom né, quando tá bebo é tudo uma galinha.

Antônio possuía ensino fundamental incompleto e ganhava 730 reais (em 2015) como auxiliar de serviços gerais, indicadores que figuravam no eixo o, destinado às categorias sociodemográficas, utilizadas para atribuição de classe: pobre. Ainda na primeira linha do quadro, o fragmento categorizado em "Posição de gênero"/"Feminilizado" ofereceu mais informações sobre a lógica das preferências eróticas:

E: Mas tu já foste pra boate, essas coisas? A: Já, pra Metrópole, lána cidade. A, aí eu não gostei não, disse pros meus amigos. E: Tu não gostaste, por que? A: Porque, assim, eu sei que ali tudo é homossexual, tá entendendo? Aí, se eu sou homossexual, não tem a mulher com mulher? Eu acho assim, eu, eu não vou ficar com homossexual que eu não sou sapatona, tá entendendo? Eu gosto de cafuçu, eu gosto de homem mesmo. De sair com homem mesmo. 
Vou fazer o quê numa boate que eu sei que é tudo veado igual a mim? Aí eu não gosto porque o veado é assim: se tem dois homens morando juntos, todos dois são veados, porque um ajuda o outro. Um dá o dinheiro, tá entendendo? O outro também dá dinheiro pra pagar o aluguel, pra pagar a luz, já eu sou diferente. Eu dou daqueles que eu fico, né, porque eles são homens mesmo. Aí eu não curto nessa zona não. Eu só curto minha parte.

Olhando vários fragmentos narrativos lançados na categoria "atributos positivos dos parceiros" do nosso quadro analítico, identificamos a presença do cafuçu como o tipo de homem desejado pelas pintosas (Eixo o/Estilização de Gênero), especialmente as mais pobres (Eixo o/Escolaridade/Renda/Ocupação). Essas constatações foram possíveis por meio de "testes de associação" não estatísticos, produzidos pragmaticamente pelo instrumento analítico e por cálculos matemáticos muito simples. 0 que Howard Becker (1997) chamou de uma quase estatística, que vai sendo utilizada pelos pesquisadores de campo durante as observações participantes, e, no nosso caso, também utilizada na análise temática das entrevistas.

É óbvio que contar não é tudo. Mas, a etapa considerada mais nobre da pesquisa qualitativa, a interpretação, a atribuição de significados aos dados analisados, somente é possível porque, de alguma forma, as tendências do campo foram dimensionadas, após a redução analítica e o estabelecimento de conexões entre as variáveis/marcadores sociais. Em outras palavras, identificar categorias êmicas, classificar os fragmentos de entrevistas e contar. Esse processo nos permitiu chegar a algumas conclusões, apresentadas para avaliação pela comunidade acadêmica (encontros e publicações) (Rios et al., 2019a, 2019b), e foram retomadas para serem novamente testadas e aprofundadas nas demais etapas da pesquisa (Rios et al., 2018; Rios, Paiva e Brignol, 2019; Rios, 2021).

\section{Redes de tramas largas}

Convém ressaltar que realizar uma pesquisa quantitativa por meio de aplicação de um questionário não se resume a marcar quesitos, implantar as respostas num banco e realizar as análises estatísticas com auxílio de um software. Escolhas sobre a composição amostral e as questões a serem utilizadas precisam ser feitas e quanto mais elas forem embasadas em reflexões teóricas sobre o campo, mais chances de o estudo aprofundar os conhecimentos sobre as realidades investigadas (Goode; Hatt, 1972).

No caso da composição amostral, é importante sublinhar que investigamos a conduta sexual de uma população que, por causa do estigma e da discriminação, invisibiliza-se publicamente, sendo, portanto, difícil de se expressar em estudos populacionais randomizados. Estávamos em busca de um recurso que permitisse a expressão da heterogeneidade das redes de sociabilidade HSH, para além de sua população mais visível - acessada nas observações e conversas informais, quase sempre com homens gays identificados em estabelecimentos comerciais, como boates, bares e saunas.

Algumas estratégias são utilizadas para construção das amostras com populações de difícil acesso, como o snowball (bola de neve), o time-location sampling (amostragem local-tempo) e a targeted sampling (amostragem orientada). Não obstante, elas trazem, em alguma medida, vieses para a amostra: a técnica de snowball tende a concentrar-se em pessoas com perfis muito similares, a amostragem local-tempo tende a selecionar apenas aqueles participantes que estão visíveis e a amostragem orientada pode superestimar a participação na população de subgrupos identificados em pesquisa qualitativa prévia, no momento de delimitar a quantidade de investigados para cada estrato. Uma quarta alternativa é o chain-referral (referência em cadeia). Ela tem sido utilizada quando o universo amostral da população de interesse faz parte de uma rede (Valente, 2010).

Um método que segue este princípio é o respondent-driven sampling (RDS) (Heckthorn, 2002). Muito utilizado em grandes estudos multicêntricos com as chamadas populações-chave para a infecção pelo HIV e de difícil acesso (usuários de drogas, HSHs, profissionais do sexo e transgêneros), o RDS foi construído baseado em pesquisas sobre redes sociais. Estas têm apontado que, em populações grandes, indivíduos estão indiretamente associados a outros membros da sociedade por meio de, 
aproximadamente, seis intermediários. Propõe-se, então, que, através de várias ondas de indicação, seja possível cobrir uma determinada população, captando sua diversidade de marcações sociais.

A amostra RDS usa um sistema de duplo incentivo (dos pares e financeiro) que teria um papel fundamental para atrair pessoas que não se sentem encorajadas a participar de pesquisas. Na preparação do estudo, a equipe não contava com profissional especializado nesta técnica e, embora tenha inspirado alguns dos elementos do desenho de composição amostral, optou-se por não cumprir as condições para análise nesse modelo. Dado os limites orçamentários, não foi ofertada nenhuma recompensa financeira aos participantes, seja por responder ou por indicar novos possíveis respondentes. Também não incluímos qualquer questão que permitisse dimensionar a rede pessoal de homossociabilidade dos participantes, fundamental para realizar as ponderações no tratamento estatístico RDS.

O que produzimos foi uma forma um pouco mais elaborada da formação de amostragem em cadeia, a partir de redes que se iniciaram entre moradores de seis municípios da RMR, garantindo a ampliação da heterogeneidade. Além disso, utilizamos uma codificação que permitiu marcar os lugares de cada participante nas cadeias. Foram recrutados residentes dos seis municípios da RMR com maiores taxas de detecção para a aids do Nordeste (BRASIL, 2013). Para iniciar as redes, voluntários/sementes foram localizados por meio de redes de relações dos pesquisadores e, quando se dispunham a serem entrevistados, também foram solicitados a indicar outros possíveis voluntários e assim sucessivamente. Tivemos então a seguinte distribuição amostral: Recife I com 43 (11,32\%) respondentes, Recife II com 125 $(32,89 \%)$, Cabo de Santo Agostinho I com 2 (o,53\%), Cabo de Santo Agostinho II com 24 (6,32\%), Ipojuca com 8 (2,11\%), Olinda I com 54 (14,21\%), Olinda II com 92 (24,21\%), Jaboatão dos Guararapes I com 1 (o,26\%), Jaboatão dos Guararapes II com 18 (4,74\%) e Igarassu I com 13 (3,42\%).

Incialmente, previa-se o limite de três pessoas indicadas por cada participante. No entanto, frente à alta quantidade de recusa (certamente porque não houvesse incentivo financeiro), ampliamos a indicação dos entrevistados para até sete pessoas. Na ocasião da entrevista, os nomes e contatos de celular/Whatsapp dos indicados foram solicitados e coube aos entrevistadores entrarem em contato com os indicados. Em adição, também solicitamos que o entrevistado entrasse em contato com os seus indicados para facilitar a abordagem do pesquisador (o que nem sempre ocorreu). Em alguns casos, o participante conduziu pessoalmente o entrevistador até a residência do novo voluntário; em outros, por conta da quantidade de recusa, o entrevistador voltava a entrar em contato com os entrevistados para solicitar novos indicados.

Mediante o progresso das aplicações dos questionários, encontraram-se algumas dificuldades. Uma delas foi a de identificar sementes para dar início à formação das redes em municípios menores. Do mesmo modo, observaram-se dificuldades das sementes desses municípios em indicar novos sujeitos e dos indicados aceitarem ser entrevistados. A equipe percebeu que os três entraves convergiam para a questão da estigmatização em relação ao fato de alguém (o entrevistado ou o indicado) ser identificado como uma pessoa que tem práticas homossexuais. O que, como sugere Richard Parker (2002), tem um peso maior nas pequenas cidades. Nesse sentido, a equipe observou que, mesmo em Recife e Olinda (cujas redes não tiveram grandes problemas em serem iniciadas e ampliadas), os sujeitos tendiam a indicar pessoas gays identificadas. Isso foi percebido em momentos em que o entrevistado conversava sobre quem indicar. Muitas vezes diziam que "fulano não daria para ser indicado”, em geral seguido por comentários relativos ao fato de não querer que as pessoas saibam que ele (o fulano) tem práticas homossexuais.

Da amostragem ao instrumento de investigação, as reflexões sobre sua produção e as qualidades dos dados capturados são fundamentais para o êxito do trabalho interpretativo. Como já mencionamos, o questionário fecha a possibilidade de respostas, impedindo que a novidade apareça. Na produção das questões do inquérito decidimos por utilizar categorias mais "universais" para capturar o modo como as pessoas se classificavam do ponto de vista do gênero, operacionalizado pela questão 
"Em relação ao seu modo de ser e se expressar, como você se percebe?”. As respostas foram: másculo, efeminado, "não sei” e "não quero responder". A opção por estas respostas e não pelas categorias nativas boy, cafuçu e pintosa deveu-se ao fato de trabalharmos com a perspectiva de alcançar redes de homens não necessariamente frequentadores dos estabelecimentos comerciais da comunidade gay, onde elas poderiam não fazer sentido.

Surpreendeu-nos o percentual de $44,8 \%$ respondentes que optaram por “não sei”, enquanto másculos e efeminados tiveram, respectivamente, 23,3\% e 31,8\%. É muito comum, entre as abordagens metodológicas em CHS aplicadas à saúde, falar-se em triangulação metodológica, onde diferentes dispositivos técnicos de coleta de dados são utilizados para abordar o fenômeno investigado (Gomes et al., 2010). Na produção etnográfica a triangulação é condição sine qua non de produção científica. 0 grande diferencial em relação a outras perspectivas de triangulações é o modo como a própria experiência pessoal dos pesquisadores, durante a coleta de dados, é utilizada para a compreensão do fenômeno. Exemplificaremos a importância dessa forma de triangular na compreensão sobre o grande percentual de escolhas pela categoria "não sei”.

Na ocasião da aplicação do inquérito, Patrício (nome fictício) comenta que "não sabia" se classificar como efeminado ou másculo, porque, de longe e para uma pessoa que não o conhece, seu tipo físico e trejeitos não assinalariam "pinta" (traços de feminilidade). No entanto, conversando com ele (sotaque gay e gestualidade), uma pessoa poderia classificá-lo como efeminado. Paulão (nome fictício), morador de um bairro popular (um dos contextos da observação participante) e respondente do inquérito, também afirmou "não saber" se classificar. Ele tem namorada e, do mesmo modo que seus "colegas de esquina”, possui a fama de "pegador" (estar sempre disponível e criando oportunidade para ter relações sexuais com as mulheres do bairro). Na ocasião da aplicação do questionário relatou ser profissional do sexo e, ao contar sobre a sauna gay onde "faz programa", passou a se utilizar de sotaque e gestual que, no olhar do entrevistador, remetiam-lhe à categoria "pintosa" (Rios et al., 2018).
As respostas acima estão sintonizadas com a recorrente menção, nas narrativas biográficas, de estratégias para fugir dos efeitos da estigmatização às homossexualidades, tentando configurar masculinidade em performances públicas, expressas em termos como "discrição", "maquiagem", "máscara" e outros. Assim, a partir desses indicadores oriundos das observações e entrevistas sugerimos que a categoria "não sei" seria expressão de fenômenos relacionados à epistemologia do armário (Sedgwick, 2007) e levantamos a hipótese de que as estilizações de gênero iriam se associar significativamente com violência, discriminação e sofrimento psíquico, efeitos da estigmatização.

A análise estatística evidenciou que embora os efeminados sofram mais violência e discriminação, aqueles que optaram por "não sei” apresentam mais sofrimento psíquico. Fenômeno que relacionamos aos altos custos subjetivos em se manter protegido da estigmatização das homossexualidades, que se atualiza sempre que um HSH agencia feminilidade (Rios et al., 2018).

\section{Considerações finais}

Situar-nos, um negócio enervante que só é bem-sucedido parcialmente, eis no que consiste a pesquisa etnográfica como experiência pessoal.

(Geertz, 1987, p. 10).

Ao longo deste trabalho, nosso argumento foi o de que contagens, estabelecimentos de conexões e atribuições de significado estarão presentes nas muitas técnicas de investigação utilizadas nas CHS, independentemente de serem localizadas como qualitativas ou quantitativas; explicativas ou compreensivas.

Tomando a metáfora de Alves (2006) para discutir os instrumentos de pesquisa, reclassificamos as técnicas de investigação em CHS usando a imagem de redes de pesca, que ajudou a nos deslocarmos da fetichização da matemática. As redes de tramas mais estreitas, como a observação participante e a entrevista biográfica, deixam mais facilmente as novidades se expressarem. Entretanto, mostramos como, a partir de uma rede de pesca intermediária (o quadro analítico), “apanhamos” o cafuçu, perdido no primeiro lance da tarrafa. 
As redes de tramas mais abertas, como o questionário, limitaram a possibilidade do novo se expressar, mas permitiram verificar a amplitude, dimensionar a recorrência das categorias e dos comportamentos identificados. A eficácia do questionário, entretanto, dependeu dos resultados das entrevistas e observações, de modo que a elaboração das questões e respostas produzisse tramas de redes adequadas ao que se queria "pescar".

Técnicas como o questionário são criticadas por usar da dicotomia para realizar o trabalho analítico, e hipersimplificar a realidade. No caso em tela, o grande percentual de escolhas pela categoria "não sei" nos levou a percorrer novamente toda a cadeia referencial de dados e resultados, dando nova roupagem aos questionamentos teóricos com relação à porosidade dos modelos binários de gênero, calcados no par masculino e feminino.

O que confere cientificidade a esta forma de operar metodologicamente não é a possibilidade de replicar a pesquisa e obter os mesmos resultados, atualizada em apresentar, na seção método dos artigos científicos, o passo a passo "frio" dos procedimentos. Também não é o uso de testes estatísticos de associação para "provar" que se mantêm de pé as supostas "frágeis" inferências construídas nas conexões entre temas e marcadores das análises de conteúdo dos dados "qualitativos", mesmo quando confrontadas à "prova dos números".

No nosso entendimento, a positividade do conhecimento oferecido para avaliação dos pares é conseguida pela explicitação de toda a cadeia referencial de dados, resultados e interpretações (Latour, 2001) e das retificações realizadas no caminho (Bachelard, 2005). Inclusive, foi por isso que apenas usamos exemplos já apresentados à comunidade acadêmica por meio de publicação em revistas científicas com revisão de pares. Artigos em que a discussão metodológica foi acontecendo por todo o texto, desde as construções dos objetos, nas introduções, operacionalizações metodológicas dos conceitos, nas seções de método, e dos procedimentos para retificações e interpretações, em seções de resultados e de discussão. Assim, não apresentamos apenas a "receita do bolo" ou método, mas os "pulos do gato", tenham eles se configurado em erros, acertos, ou adequações no processo de produção do conhecimento.

Em síntese, a objetividade científica vai se configurar na elaboração de documentos científicos em que o(a) leitor(a) não apenas seja convencido(a) das conclusões às quais os(as) pesquisadores(as) chegaram, mas também disponha de elementos para chegar a conclusões diferentes. Uma forma de avaliação de cientificidade que se aproxima a um só tempo dos critérios de cientificidade de Pooper (2006) e de Bachelard (2005).

Situamos nossa forma de operar a pesquisa como etnográfica e tomamos como mote para a produção deste texto o estranhamento sobre o uso do inquérito como modo de coleta de dados. Queremos destacar que, desde os estudos etnográficos em “sociedades simples”, as contagens estão presentes nos inventários e censos que envolvem, por exemplo, a descoberta de algoritmos matemáticos que representam os complexos sistemas de parentesco (cf. Rivers, 1991).

Queremos sugerir que o que vai caracterizar um estudo como etnográfico não são as técnicas de coleta de dados, mas o modo como operar com elas. Os estudos etnográficos não vão deixar de reduzir, mas vão recolocar a redução em perspectiva com a totalidade sociocultural e as singularidades de pesquisadores(as) e pesquisados(as). No dizer de Geertz (1987), vai exigir dos(as) pesquisadores(as) situarem-se no processo de compreender as estruturas conceptuais e apresentar, em cada caso estudado, o papel da cultura na vida humana. Um conhecimento sobre um dado objeto sempre singular, no sentido de que é "àquela pequena parte dele que os nossos informantes nos podem levar a compreender" (Geertz, 1987, p. 14) e, portanto, necessita de circunstanciação.

Retomando as análises de nosso projeto, de trás para frente, o processo analítico e interpretativo dos testes estatísticos foi realizado produzindo interlocução entre os dados oriundos de entrevistas e observações, incluindo observações participantes do próprio processo de aplicação dos questionários, sempre colocando a presença do(a) pesquisador(a) que efetivamente coletou o dado como condição de produção analítico-interpretativa. 
Não é demais relembrar que nesse movimento também se enquadra aquele procedimento utilizado pelos(as) próprios(as) entrevistadores(as) para classificarem, a partir do que aprenderam sobre a lógica nativa de operar com gênero, os seus interlocutores na entrevista. Um processo em que os produtos das técnicas de coleta e análise vão sendo checados em sua pertinência a cada passo, e que deve permitir sempre voltar aos registros, produzir novas análises e interpretações, adensando cada vez mais as descrições.

\section{Referências}

ALVES, R. Filosofia da ciência: introdução ao jogo e a suas regras. São Paulo: Edições Loyola, 2006.

AYRES, J. R. C. M.; PAIVA, V.; BUCHALLA, C. M. Direitos Humanos e Vulnerabilidade na Prevenção e Promoção da Saúde: uma introdução. In: PAIVA, V.; AYRES, J. R.; BUCHALLA, C. M. (Org.). Da doença à cidadania. Curitiba: Juruá Editora, 2012. p. 9-22.

BACHELARD, G. A formação do espírito científico. Rio de Janeiro: Contraponto, 2005.

BECKER, H. Métodos de pesquisa em ciências sociais. São Paulo: HUCITEC, 1997.

BRASIL. Boletim Epidemiológico - Aids e DST. Brasília: Ministério da Saúde, 2013.

BUTLER, Judith. Problemas de Gênero: Feminismo e Subversão da Identidade. Rio de Janeiro, Editora Civilização Brasileira, 2003.

DILTHEY, W. Psicologia e compreensão. Lisboa: Edições 70, 2002.

FRY, P. Para inglês ver: identidade e política na cultura brasileira. Rio de Janeiro: Zahar, 1982.

GEERTZ, C. A interpretação das culturas. Rio de Janeiro: Zahar, 1987.

GIDDENS, A. Política, sociologia e teoria social: encontros com o pensamento social clássico e contemporâneo. São Paulo: Fundação Editora da Unesp, 1998.

GOMES, R. et al. Organização, processamento, análise e interpretação de dados: o desafio da triangulação. In: MINAYO, M. C. S.; ASSIS, S. G.; SOUZA, E. R. (Org.). Avaliação por triangulação de métodos: Abordagem de Programas Sociais. Rio de Janeiro: Fiocruz, 2010. p. 185-221.

GOODE, W.; HATT, P. Métodos em pesquisa social. São Paulo: Editora Nacional, 1972.

HECKTHORN, D. Respondent-Driven Sampling II: Deriving valid Population Estimates from chain-referral samples of hidden populations. Social Problems, Connecticut, v. 49, n. 1, p. 11-34, 2002. Disponível em: <http://www. respondentdrivensampling.org/reports/RDS2. pdf $>$. Acesso em: 23 set. 2021.

LATOUR, B. A Esperança de Pandora: ensaios sobre a realidade dos estudos científicos. Bauru: EDUSC, 2001.

MINAYO, C. Análise qualitativa: teoria, passos e fidedignidade. Cienc, Saude Colet., Rio de Janeiro, v. 17, n. 3, p. 621-626, 2012. DOI: 10.1590/S141381232012000300007

PEIRANO, M. Etnografia não é método. Horizontes Antropológicos, Porto Alegre, v. 20, n. 42, p. 377-91, 2014. DOI: 10.159o/s0104-71832014000200015

PARKER, R. Abaixo do Equador - culturas do desejo: Homossexualidade masculina e comunidade gay no Brasil. Rio de Janeiro: Record, 2002.

POPPER, K. A lógica da pesquisa científica. São Paulo: Cultrix, 2006.

RAXACH, J. et al. Práticas sexuais e conscientização sobre AIDS: uma pesquisa sobre o comportamento homossexual e bissexual. Rio de Janeiro: ABIA, 2007.

PASCOM, A.; ARRUDA, M.; SIMÃO, M. (Org.). Pesquisa de Conhecimentos, Atitudes e Práticas na População Brasileira de 15 a 64 anos 2008. Brasília: Ministério da Saúde, 2011.

RIOS, L. Sexualidade e prevenção entre homens que fazem sexo com homens nos contextos das pandemias de AIDS e da Covid-19. Ciência \& Saúde Coletiva, Rio de Janeiro, v. 26, n. 5 , p. 1853-1862, 2021. Disponível em: < disponível em: http://www.cienciaesaudecoletiva.com.br/ artigos/sexualidade-e-prevencao-entre-homensque-fazem-sexo-com-homens-nos-contextos-daspandemias-de-aids-e-da-covid19/17937?id=17937 >. Acesso em: 17 set. 2021. 
RIOS, L. et al. "Foi como se a gente tivesse visto a morte": estigmatização, sofrimento psíquico e homossexualidade. Laplage em Revista, [S.l.], v. 4 , n. 1, p. 140-158, 2018. DOI: 10.24115/S24466220201841442p.140-158

RIOS, L. et al. Posições sexuais, estilos corporais e risco para o HIV entre homens que fazem sexo com homens no Recife (Brasil). Ciência \& Saúde Coletiva, Rio de Janeiro, v. 24, n. 3, p. 973-982, 2019a. DOI: 10.1590/1413-81232018243.34092016 RIOS, L. et al. 0 drama do sexo desprotegido: estilizações corporais e emoções na gestão de risco para HIV entre homens que fazem sexo com homens. Sexualidad, salud y sociedad, Rio de Janeiro, v. 32, p. 65-89, maio/ago. 2019b. DOI: 10.1590/1984-6487.sess.2019-32.05.a

RIOS, L., PAIVA, V., BRIGNOL, S. Passivos, ativos and versáteis: men who have sex with men, sexual positions and vulnerability to HIV infection in the Northeast of Brazil. Culture health \& sexuality, [S.l.], v. 21, n. 5, p. 510-525, 2019.

DOI: $10.1080 / 13691058.2018 .1491063$
RIVERS, W. O método genealógico na pesquisa antropológica. In: OLIVEIRA, R. C. (Org.), A Antropologia de Rivers. Campinas: Editora da Unicamp, 1991. p. 51-67.

RUBIN, G. The traffic in women: Notes on the political economy of sex. In: REITER, R. (Ed.). Toward an Anthropology of Women. New York: Monthly Review, 1975. p. 157-210.

SEDGWICK, E. A epistemologia do armário. Cadernos Pagu, Campinas, n. 28, p. 19-54, 2007. DOI: 10.1590/So104-83332007000100003

VALENTE, T. Social networks and health: Models, methods, and applications. Oxford: Oxford University Press, 2010.

WEBER, M. A "objetividade" do conhecimento nas Ciências Sociais. In: COHN, G. Max Weber.

São Paulo: Ática, 1997. p. 13-109.

WITTGENSTEIN, L. Investigaciones filosóficas. Traducción, introducción y notas críticas de Jesús Padilla Gálvez. Madrid: Editorial Trotta, 2017.

\section{Contribuições dos autores}

Rios realizou a formulação conceitual do projeto e pela coordenação das fases I, 2 e 3 da pesquisa. Adrião colaborou com o primeiro autor na coordenação das fases 4,5 e 6 do trabalho de campo. Ambos trabalharam conjuntamente na elaboração do presente artigo.

Recebido: 12/05/2021

Aprovado: 20/09/2021 